\title{
ERRATUM
}

\section{A unique iron-sulfur cluster is crucial for oxygen tolerance of a [NiFe]-hydrogenase}

Tobias Goris, Annemarie F Wait, Miguel Saggu, Johannes Fritsch, Nina Heidary, Matthias Stein, Ingo Zebger,

Friedhelm Lendzian, Fraser A Armstrong, Bärbel Friedrich \& Oliver Lenz

Nat. Chem. Biol. 7, 310-318 (2011); published online 9 March 2011; corrected after print 1 July 2011

In the version of this article initially published, an arrow was inadvertently omitted from Figure 7 . The error has been corrected in the HTML and PDF versions of the article.

\section{ERRATUM}

\section{A unique iron-sulfur cluster is crucial for oxygen tolerance of a [NiFe]-hydrogenase}

Tobias Goris, Annemarie F Wait, Miguel Saggu, Johannes Fritsch, Nina Heidary, Matthias Stein, Ingo Zebger,

Friedhelm Lendzian, Fraser A Armstrong, Bärbel Friedrich \& Oliver Lenz

Nat. Chem. Biol. 7, 310-318 (2011); published online 9 March 2011; corrected after print 1 July and 1 August 2011

In the previous version of this article, a water molecule was mislabeled in Figure 7 and an error was inadvertently introduced into the journal title. These errors have been corrected in the HTML and PDF versions of this article.

\section{CORRIGENDUM}

\section{Behind the folding funnel diagram}

Martin Karplus

Nat. Chem. Biol. 7, 401-404 (2011); published online 17 June 2011; corrected after print 14 July 2011

In the version of this article initially published, there was an error in the abstract that stated an increase in the configurational entropy hinders folding, but it should read that there is a decrease in the configurational entropy that hinders folding. The error has been corrected in the HTML and PDF versions of the article.

\section{ERRATUM}

\section{A chemical probe selectively inhibits G9a and GLP methyltransferase activity in cells}

Masoud Vedadi, Dalia Barsyte-Lovejoy, Feng Liu, Sylvie Rival-Gervier, Abdellah Allali-Hassani, Viviane Labrie, Tim J Wigle, Peter A DiMaggio, Gregory A Wasney, Alena Siarheyeva, Aiping Dong, Wolfram Tempel, Sun-Chong Wang, Xin Chen, Irene Chau, Thomas J Mangano, Xi-ping Huang, Catherine D Simpson, Samantha G Pattenden, Jacqueline L Norris, Dmitri B Kireev, Ashutosh Tripathy, Aled Edwards, Bryan L Roth, William P Janzen, Benjamin A Garcia, Arturas Petronis, James Ellis, Peter J Brown, Stephen V Frye, Cheryl H Arrowsmith \& Jian Jin

Nat. Chem. Biol. 7, 566-574 (2011); published online 10 July 2011; corrected after print 26 July 2011

In the version of this article initially published, in paragraph 3 of the results section entitled "UNC0638 is a potent and substratecompetitive inhibitor," the units for the association rate $(\mathrm{ka})$ were listed incorrectly. The correct unit is $1 /$ Ms. This error has been corrected in the HTML and PDF versions of the article. 